\title{
ENGLISH WAR DISCOURSE: DIACHRONIC ASPECT
}

\author{
Natalia A. Srebryanskaya \\ Voronezh State Pedagogical University, Voronezh, Russia
}

\begin{abstract}
The article considers the features of English military discourse development over several centuries $\left(11^{\text {th }}-21^{\text {st }}\right.$ centuries). Particular attention is paid to modern signs of the war discourse, which is treated as a part of political discourse. The material for diachronic analysis is represented with the written sources of ancient and Middle English epics. Modern English military discourse is considered on the basis of media publications. Historical sources give information about the methods of waging war with the use of steel and firearms, its scale, and the heroism of warriors. The analysis undertaken has made it possible to single out the features of modern English discourse of war: the use of euphemisms, numerous neologisms and techniques of speech manipulation. Euphemisms are often represented with lexemes from dictionary entries referring to the word war or lexical substitutes with the most generalized non-specific semantics. Neologisms of military discourse arise as a result of linguistic and extralinguistic factors. Linguistic factors are the creation and use of euphemisms for statements about the unsightly facts of war. Extralinguistic factors include the emergence of new types of warfare and military technology. Some new types of warfare that use information technology are considered. Conclusions concerning international character of military terminology and rapid development of war discourse at present are drawn in the article.

Key words: discourse, war discourse, diachrony, lexis, synonymy, euphemism, neologism, language manipulation.

Citation. Srebryanskaya N.A. English War Discourse: Diachronic Aspect. Vestnik Volgogradskogo gosudarstvennogo universiteta. Seriya 2. Yazykoznanie [Science Journal of Volgograd State University. Linguistics], 2020, vol. 19, no. 3, pp. 97-106. (in Russian). DOI: https://doi.org/10.15688/jvolsu2.2020.3.9

\section{АНГЛОЯЗЫЧНЫЙ ДИСКУРС ВОЙНЫ В ДИАХРОНИЧЕСКОМ АСПЕКТЕ}

\author{
Наталья Анатольевна Сребрянская
}

Воронежский государственный педагогический университет, г. Воронеж, Россия

\footnotetext{
Аннотация. В статье на материале письменных источников (эпоса, художественных произведений и текстов СМИ) охарактеризована динамика англоязычного военного дискурса с XI по XXI век. В результате анализа семантики слов синонимических рядов с доминантой war, их сочетаемости и словообразовательного потенциала показано, что в древне- и среднеанглийских источниках война представлена как столкновение вооруженных людей, обозначены способы ведения войны с помощью холодного и огнестрельного оружия, ее масштабы, героизм воинов. Установлено, что современный военный дискурс отличается эвфемизацией, неологизацией и использованием приемов речевого манипулирования. Определено, что в качестве эвфемизмов используются лексемы из словарных дефиниций слова war или лексические субституты с максимально обобщенной семан¿ тикой. Неологизмы военного дискурса появляются в результате действия лингвистических и экстралингвистических факторов. К лингвистическим факторам относится эвфемизация, позволяющая скрыть неприглядные стороны войны, к экстралингвистическим - возникновение новых видов войны и развитие военных технологий. Описываются лексические единицы, номинирующие новые виды войны с примением информационных техо̊̆ нологий. Делается вывод о быстром развитии дискурса войны в настоящее время.

Ключевые слова: дискурс, дискурс войны, диахрония, лексика, синонимия, эвфемизм, неологизм, языковое манипулирование.
} 
Цитирование. Сребрянская Н. А. Англоязычный дискурс войны в диахроническом аспекте // Вестник Волгоградского государственного университета. Серия 2, Языкознание. - 2020. - T. 19, № 3. - C. 97-106. - DOI: https://doi.org/10.15688/jvolsu2.2020.3.9

\section{Введение}

Динамические аспекты дискурса в последние годы все чаще становятся объектом исследования лингвистов, поскольку выявление исторических характеристик того или иного дискурса позволяет определить основные направления и тенденции его развития. Как справедливо указывают Е.Ю. Ильинова и Л.А. Кочетова, характеризуя этапы диахронического изучения дискурса, «the second step in the diachronic discourse oriented analysis has to be aimed at comparing discourse realizationsin textual and language unities in definite time periods in order to make preparations for the third step, which is aimed at tracing vectors of discourse diachronic development» [Ilyinova, Kochetova, 2016, с. 23] - Второй шаг в диахроническом анализе дискурса должен быть направлен на сравнение реализаций дискурса в текстовых и языковых единствах в определенные периоды времени, чтобы подготовиться к третьему шагу, который направлен на отслеживание векторов диахронического развития дискурса (здесь и далее перевод наш. $-H$. C.).

Поскольку любой дискурс состоит из множества различных единиц языка и является, по словам 3. Хэрриса, простым сцеплением фраз, непрерывным высказыванием [Harris, 1952, p. 3], значимые сведения для определения тенденций развития дискурса того или иного вида можно получить в результате анализа его лексической наполняемости на разных временных срезах.

Объектом исследования в статье стал англоязычный военный дискурс (дискурс войны). Установление некоторых его лексических особенностей в исторической динамикепозволит выявить языковые приемы, используемые в нем, и определить векторы его развития. Для этого необходимо решить следующие задачи:

1) рассмотреть на материале письменных источников лексические единицы и словосочетания, функционирующие в дискурсе войны в древне- и среднеанглийский периоды;
2) выявить на материале письменных источников лексические особенности современного дискурса войны;

3) сравнить лексические характеристики дискурса войны в разные периоды его существования.

\section{Материал и методы исследования}

В качестве материала для исследования дискурса войны в древнеанглийский период был избран письменный памятник «Beowulf» («Беовульф»), в среднеанглийский период рыцарские романы «Sir Gawain and the Green Knight» («Сэр Гавейн и зеленый рыцарь») и «Havelok the Dane» («Хэвлок Датчанин»), coдержание которых связано с темой войны. Для изучения англоязычного дискурса войны XX в. использовались художественные произведения (W. Falkner «Soldier's Рау» («Солдатская награда») и Е. Hamingway «Farewell to Arms» («Прощай, оружие»)) и тексты в широком доступе в сети Интернет: речи политиков, статьи в СМИ; для изучения военного дискурса первых десятилетий XXI в. - тексты СМИ как наиболее быстро и экспрессивно реагирующие на события в мире.

При проведении исследования применялись методы компонентного, словообразовательного и этимологического анализа лексики, а также использовался контекстуальный метод. Тексты на древне- и среднеанглийском языках рассматривались на предмет выявления лексики со значением «война», «бой», «сражение». Значения древне- и среднеанглийских лексических единиц определялись по «Old English Translator», «Middle English Dictionary»; современных лексем - по «Essential British English Dictionary» и «Essential American English Dictionary». С помощью «Etymology Dictionary» устанавливались причины номинации различных видов боев, битв, сражений. Сплошная выборка из текстов позволила обнаружить синонимические наименования войны и ее видов, словосочетания с этими синонимами, указывающие на способы ведения войны и военные технологии, а также контек- 
стуальную семантику лексем со значением «война». Для установления доминанты семантических рядов и уточнения значения слова использовался метод субституции.

\section{Результаты и обсуждение}

\section{Дискурс войны в древности}

«Беовульф» - эпическая поэма, которая ввиду своей тематики предоставляет богатый материал для исследования дискурса войны. Ключевое слово дискурса - war (война). Поэма «Беовульф» известна богатством синонимов. Методом сплошной выборки нами был получен ряд из 17 синонимичных существительных, в семантике которых, согласно данным «Old English Translator», представлен тот или иной компонент значения «война»: gielpplega (war), beadu (battle, war), hild (battle, war), orlege (war, strife, hostility), orlegní (war, hostility), sacu (conflict, war, battle, feud, contention), wig (war, battle), folcgewinn (fighting, war), purhgefeoht (war), wignop (warfare, war), woelnip (deadly hostility, war), gúp (war, battle, fight, bellum), comp (contest, war, battle, warfare), ecgpracu (hot contest, sword strength war or savage courage), gefeoht (war, fight, fighting), ampe (fight, battle, war, conflict), unsibb (war). Все единицы имеют сему 'war', 6 единиц - 'battle', 4 - 'fight', 3 'hostility', по 2 - 'conflict' и 'contest'. Способность лексем к взаимозаменяемости является критерием синонимии, а способность субституции признаком доминаты синонимического ряда [Белов, 2018]. Поскольку лексема war способна заменить собой остальные лексемы, можно заключить, что она представляет собой доминанту данного синонимического ряда.

Отметим, что некоторые композитные единицы указывают на виды оружия, применяемого в войне: gární (spear-battle, spear-war / битва на копьях), ecghete (sword-hatred, hostile war / война на мечах, враждебная война). О виде оружия сообщает и лексема beadu. B «Etymology Dictionary» указывается, что это слово происходит от глагола со значением «beat with a stick, thrash» (бить палкой, молотить) и существительного со значением «heavy wooden mallet» (тяжелая деревянная колотушка), следовательно, $b e a d u$ - это бой на палках или дубинах.
Таким образом, анализ синонимичных существительных со значением «война», функционирующих в поэме «Beowulf», показал, что в древнеанглийском военном дискурсе война представлена как бой, битва, вооруженное столкновение, схватка.

Интересные наблюдения можно сделать в результате анализа композитов. Сложные древнеанглийские существительные с компонентом 'war' показывают, что война чаще всего воспринимается как опасное и жестокое дело: herebróga (dread of war / ужасы войны), herecirm - (cry / плач), heregung (harrying, harrowing, plundering, devastation / мучения, грабеж, разруха), herehand (violence of war / военное насилие), herenij (hostility, enmity / враждебность, неприязнь), wighete (hate that leads to war / ненависть, ведущая к войне). Война - это слава, удача, везение: gúphrép, cesctír (glory in war / слава в войне), beadoróf (renowned, bold in war / прославленный, смелый в войне), heresped, wígspéd (success in war / успех на войне), sigorspéd (good fortune in war, abundant success / большая удача на войне, большой успех), wigbléd (luck in war / удача на войне). Война - это оружие, доспехи, обмундирование: heorusceorp (war equipments / военное обмундирование), wigwoepen, hildewoe hildewoepen (a weapon of war / военное оружие), wigwoegn (war chariot / военная колесница), gúðcroft (war craft / военный корабль), sciphere (a collection of ships of war, a naval force fleet, a fleet of war squadron / эскадра военных кораблей, военный флот), wlghyrst (the trappings of war / атрибуты войны).

\section{Дискурс войны в среднеанглийский период}

Методом сплошной выборки из текста произведений было получено 13 лексем, которые, согласно «Middle English Dictionary», содержат компоненты значения 'war', 'fight', 'battle' и представляют синонимический ряд с общим значением «война»: ware (defense, protection / оборона, защита); werre (large-scale military conflict between countries, peoples, rulers / крупномасштабный военный конфликт между странами, народами, правителями), batayl, bataille (battle / бой, баталия), fyzt, feoht (fight 
/ борьба), hostilitẹ (hostile action, hostility / враждебное действие, враждебность), strīfe (dissension, discord, contention; quarreling; hostility, enmity; civil disorder / разногласие, раздор, ссора, враждебность, неприязнь; гражданские беспорядки), enemite (a) a hostile feeling or attitude, rivalry, malice; also, a hostile act; b) the action of an enemy, an attack / a) враждебное чувство или отношение, соперничество, злоба; также враждебный акт; b) действия врага, атака); conflict (a) an armed encounter, a battle; b) a struggle; a quarrel; c) an attack or assault / a) вооруженное столкновение, битва, b) борьба; ссора; с) нападение), encóuntre (a) hostile encounter, combat, battle; b) opposing forces, enemies / a) враждебное столкновение, бой, битва; b) противостоящие силы, враги), asaut (an armed attack or encounter; a military expedition; a siege; / вооруженное нападение или столкновение; военная экспедиция; осада); iwin (strife, struggle, war; a battle, conflict / борьба, война; битва, конфликт); sege, asēge (a siege (as of a city); setten asege, lay siege / осада), iwealc (strife, conflict; a military engagement / раздор, конфликт; военное сражение).

Выявленные словосочетания среднеанглийского периода показывают, что англичане понимали войну как необходимость защищать свою землю и народ: to witte wheder he wold fynde a man to fight with Colbrande for the righte of the kingdom (to know whether he would find a man to fight with Colbrande for right of the kingdom / знать, сможет ли он найти человека, чтобы сражаться с Колбрандом за права королевства). Они считали, что сражаться надо, отдавая все силы, до победы: And fouhten so pei woren wode, Pat pe swot ran fro be crune To the fet rith pere adune (And fought so as if they were mad that sweat ran from head to the feet down / И сражались, как сумасшедшие, так что пот бежал от головы до ног); pei fouhten so füriǒust th thăre bothe fellen of theire horsen and bataillened bat pe swot ran fro pe hèd (they fought so furiously that both fell off from their horses and battled so that sweat ran from their heads / они бились так яростно, что оба упали с коней и сражались так, что пот бежал по лицу). Война - это храбрость, благородство: thy werreiours holden pe best and pe vailaunt of thōse rìden mail-clad to fight (thy warriors are held for the best and the most valiant of those who ride mail-clad to the fight / твоих воинов считают самыми лучшими и самыми доблестными из тех, кто в кольчуге едет на битву); 'twas a bold werreiour (it was a brave warrior / это был храбрый воин); pe wisest and pe worthiest in be world arren thei and wel proven in al knight sporte (the wisest and the worthiest of this world are they, and well proven in all knightly sports / они самые мудрые и достойные в этом мире, и все хорошо проявили себя в рыцарских состязаниях).

В то же время война воспринимается как опасное дело, риск для жизни: He was oft in daungẹerof dèth (he was often in danger of death / над ним часто нависала опасность смерти), doubtless he had been dead and slain full oft (doubtless he was killed and was dead / несомненно, он был убит); Were werre and wrake (were war and waste / там была война и разруха). Война - источник несчастий: Loude crye was per kest of clerkez and oper of werre (the cast of clerks and others cried loudly because of war / все работники громко кричали, узнав о войне). Следует отметить и еще одну группу словосочетаний со значением «храбрый воин сам не ищет битвы, мир лучше войны»: I seche no werre (I seek no war / я не ищу войны); untō̆cǒme I mit pes (I come with peace / я пришел с миром); If pou craue batayl bare, here faylez pou not to fyzt (if it is battle that thou cravest, thou shalt not fail of a fight here / если ты жаждешь битвы, ты не проиграешь здесь); I passe as in pes, and no plyzt seche (I pass in peace and seek no quarrel / я пришел с миром и не ищу битвы); frayst I no fyzt (I demand no fight / я не прошу боя) (Sir Gawain and the Green Knight; Havelok the Dane).

\section{Дискурс войны в $X X$ веке}

Для анализа дискурса этого периода синонимический ряд с лексемой war в качестве доминанты был получен на базе произведений американской литературы и словарей (Essential British English Dictionary; Essential American English Dictionary): war, warfare (война); clash (столкновение); confrontation (противоборство); combat (бой); hostilities (воен- 
ные действия); collision (противоречие интересов); discord (вражда); fight, fighting (борьба); battle (битва, сражение, бой); enmity (вражда); strife (борьба); strike (удар, атака); struggle (борьба); bloodshed (кровопролитие); crusade (поход, кампания); jihad (джихад); offensive (атакующая военная кампания, атака, наступление); skirmish (стычка, схватка); campaign (кампания, поход); engagement (бой, схватка). Как видно, синонимический ряд с доминантой war в английском языке $\mathrm{XX}$ в. включает больше лексем, чем в древне- и среднеанглийский периоды (21 лексическая единица). Появились новые единицы: confrontation, bloodshed, crusade, jihad, offensive, skirmish, campaign, engagement.

Как и при исследовании военного дискурса в древне- и среднеанглийский периоды, анализ дискурса в XX в. требует рассмотрения словосочетаний с лексемами синонимического ряда с доминантой war, а также выявления смысла контекстов с данными лексемами. Словосочетания, полученные при сплошной выборке из художественных произведений и текстов СМИ, соотносятся с единицами, описанными в работе Л.Н. Венедиктовой [Венедиктова, 2004]. В военном дискурсе XX в. выделяется большая группа прилагательных, которые образуют словосочетания с лексемой war и определяют специфику видов войны. Они широко употребляются в сфере политики и международных отношений для номинации разновидностей войн: ideological war (идеологическая война), civil war (гражданская война), cold war (холодная война), colonial war (колониальная война), aerial war (воздушная война), just war (справедливая война), world war (мировая война), war of liberation (освободительная война), nuclear war (ядерная война). Большинство этих прилагательных непосредственно связаны с реалиями $\mathrm{XX}$ в. и ранее существовать не могли. Отличием военного дискурса XX в. является то, что словосочетания часто номинируют разные виды войны.

\section{Дискурс войны в XXI веке}

Остановимся более подробно на современном дискурсе войны, поскольку за последние десятилетия он претерпел значительные изменения.
Из словарей и текстов был извлечен синонимический ряд лексем со значением «война»: war, warfare (война); campaign (кампания, поход); engagement (бой, схватка); confrontation (противоборство); hostilities (военные действия); collision (коллизия, столкновение); fight, fighting (борьба); enmity (вражда); strife (борьба); strike (удар, атака); struggle (борьба); clash (столкновение); crusade (поход, кампания); jihad (джихад); offensive (наступательная военная операция, атака, наступление); skirmish (стычка, схватка). Появились новые термины, зафиксированные в «Military History Encyclopedia»: terrorism (systematic use of violence to achieve a specific normally political aim / систематическое использование насилия для достижения особых, обычно политических целей); hijacking (a method of terrorism / метод терроризма).

Сочетания лексемы war с прилагательными представляют собой наименования видов войн: parawar, super war, proxy war, cyber war, surrogate war, informational war, nontraditional war, hybrid war, asymmetric war, sofa war и др. Они отличаются и от словосочетаний последнего десятилетия ХХ в., приведенных в работе Л.Н. Венедиктовой, что свидетельствует о быстрых изменениях в данном дискурсе и, следовательно, его быстром развитии в последние десятилетия.

Новыми в дискурсе войны являются и сочетания special operation, stripping, symmetrical response, mirror response, line of contact. Эти нейтральные в системе языка и иногда даже с обобщенным значением лексические единицы (special operation) в контексте приобретают вполне конкретное значение - военные действия. Они связаны с конфронтацией, противостоянием, противоборством. Имеет место вуалирование негативной семантики лексем с помощью нейтральных и даже «пустых» по значению слов, которые выполняют функцию эвфемизации - замены грубой или табуированной лексики на лингвистически нейтральное или смягченное выражение [Москвин, 2001, с. 58]; приема лингвистического улучшения, цель которого состоит в подборе приемлемых слов и понятий взамен тех, которые по некоторым причинам неприемлемы [Гращенков, 2015, с. 172]; маскировке явления [Логунова, 2014, с. 109]. 
В дискурсе представлены и термины, разработанные для называния новых технологий ведения войны: distributed combined parawar, spasmodic sudden escalation of conflict, escalation of controllability loss, modern civil and military technologies, air strike, irreparable losses, liquidation и др. Они указывают на стремительное обновление лексики войны. В современном военном дискурсе используются приемы языкового манипулирования, которые стали одной из важнейших лингвистических характеристик дискурса войны. Дж. Кунерт говорит о том, что дипломатия выработала свой язык, политики должны следовать правилам политкорректности, к их речи предъявляются особые требования. Для того чтобы политическая коммуникация была эффективной, дипломаты прибегают к искажению объективной реальности, подмене понятий [Kunerth, 2006]. Следует отметить и другие важные лингвистические признаки современного военного дискурса - его неологизацию и эвфемизацию. Как отмечает Е.И. Шейгал, «эвфемистическое переименование представляет собой результат своеобразного компромисса между семантикой (отражение сущности денотата) и прагматикой (отражение интересов говорящего). Эвфемизмом обозначается нечто, что по логике вещей следовало бы оценить отрицательно, но интересы говорящего (политическая выгода) заставляют оценить это положительно» [Шейгал, 2000, с. 208].

Активно используемый прием эвфемизации в военном дискурсе-генерализация. По мнению Л.С. Яровой, прием относится к наиболее продуктивным и используется преимушественно в политическом языке, СМИ, при назывании преступлений и экономических явлений [Яровая, 2012, с. 112]. В военном дискурсе примерами генерализации могут служить эвфемизмы event, situation, engagement, response. Для эвфемизации военной лексики возможно применение метонимии: Washington announced, Moscow declares, sofas / sofa troops request sanctions, programs throw viruses. Особенность данного приема состоит в том, что «метонимия в данном случае выполняет не только референциальную функцию, но и функцию обеспечения понимания целого через его часть, а также части посредством целого или другой части» [Порохницкая, 2012, с. 125].
Одним из приемов эвфемизации негативной лексики является использование словарной дефиниции того слова, которое может вызвать неприятные ощущения. Так, вместо существительного war употребляется intense armed conflict (вооруженный конфликт, столкновение). О жертвах среди мирного населения в период военных действий говорят wartime costs (потери военного времени). По мнению Е.И. Шейгал, «эвфемизмы, связанные с обозначением военных действий и вооруженных конфликтов, составляют одну из наиболее значимых групп политических эвфемизмов» [Шейгал, 2000, с. 199]. Создание новых нейтральных наименований для называния неприглядных явлений - характерная черта новояза, описанного Дж. Оруэллом (подробнее об этом см.: [Сребрянская, Мартынова, 2011]).

Проанализируем значение некоторых новых наименований войны, приведенных выше. Термин information war (information warfare) не зафиксирован в словарях. В одной из журналистских публикаций информационная война определяется следующим образом: «Information warfare combines electronic warfare, cyberwarfare and psy-ops (psychological operations) into a single fighting organisation» (What-is-information-warfare?) - Информационная война сочетает электронные средства ведения войны, кибероружие и психологические операции.

В войне, названной information warfare, используются такие технологии, как сбор тактической информации (collecting tactical information), распространение пропаганды и дезинформации для деморализации оппонента и общественности (spreading propaganda and disinformation to demoralize or manipulate the opponent and the public), снижение качества информации оппонента (undermining the quality of opponent information), отрицание сбора информации об оппоненте (denying the opponent the opportunity to collect information) [Damjanović, 2017]. Данные английские словосочетания также отличаются новизной.

Hybrid warfare (гибридная война) - вид враждебных действий, при котором нападающая сторона подавляет своего оппонента, используя сочетание скрытых операций, диверсий, кибервойны. Гибридная война по сути тоже является информационной войной. В апреле 
2016 г. во время визита в США президент Украины П.А. Порошенко заявил, что против его страны ведется гибридная война. Комментируя редакционную статью газеты «The New York Times», в которой говорилось о коррупции в высшем украинском руководстве, президент Петр Порошенко заявил, что фейковые сообщения России об Украине - часть гибридной войны со стороны России («part of the Russian hybrid war») (Poroshenko). Таким образом, П.А. Порошенко определяет гибридную войну как распространение ложной, дискредитирующей информации, двойную жизнь, то есть информационную войну. Ср.: Гибридность - это политика лжи, кто кого переврет; это информационная война (Эпштейн).

Таким образом, в последние десятилетия появились новые военные термины, в том числе и наименования войны. Они связаны с информационными технологиями.

Новые термины успешно ассимилировались в английском языке, о чем свидетельствует образование производных словосочетаний на базе исходного термина. Так, появились information operations (информационные операции), sofa army (диванная армия), sofa troops (диванные войска).

Современные цифровые технологии предопределили появление неологизмов technological warfare (технологическиая война), digital war (цифровая война): «Digital War is understood as the ways in which digital technologies and media are transforming how wars are fought, lived, represented, reported, known, conceptualised, remembered and forgotten» (Digital War) - Под цифровой войной понимаются способы, с помощью которых цифровые технологии и средства массовой информации преобразуют то, как люди ведут, переживают, представляют, концептуализируют, запоминают и забывают войны.

В работе Л.Н. Венедиктовой, изданной в 2004 г., указанные неологизмы не приводятся, что свидетельствует о стремительном изменении военного дискурса в первые десятилетия XXI века.

\section{Выводы}

Выявленная лексическая наполняемость дискурса войны в разные периоды его развития позволило прийти к следующим выводам.
1. Дискурс войны является подвижной структурой.

2. Синонимические ряды с доминантой war на протяжении развития языка и дискурса постоянно пополняются. В древне- и среднеанглийский периоды война понималась как бой, битва с применением холодного и огнестрельного оружия.

3. Словосочетания с прилагательными показывают, что в древне- и среднеанглийский периоды контекстуальное значение лексем со значением «война» менялись мало. В XXXXI вв. дискурс войны демонстрирует высокий темп развития за счет образования новых единиц в результате появления новых видов войны, новых технологий и нового оружия.

4. Быстрая обновляемость дискурса войны в последние годы связана не только с лингвистическими, но и с экстралингвистическими факторами. Дискурс войны стал частью политического дискурса, что неизбежно приводит к применению политических технологий языкового манипулирования. Происходит значительная эвфемизация лексики, связанной с войной, с целью скрыть негативные явления. Используется лексика с расплывчатым нейтральным значением, которая в дискурсе войны приобрела негативное значение. Подобные языковые приемы применяются для введения в заблуждение и манипулирования сознанием людей.

Все это свидетельствует о том, что сегодня язык стал инструментом информационной войны.

\section{СПИСОК ЛИТЕРАТУРЫ}

Белов В. А., 2018. Взаимозаменяемость как критерий синонимии (экспериментальное и корпусное исследование) // Вестник Санкт-Петербургского университета. Язык и культура. T. 15, № 3. C. 390-407. DOI: https://doi.org/ 10.21638/spbu09.2018.306.

Венедиктова Л. Н., 2004. Концепт «война» в языковой картине мира (сопоставительное исследование на материале английского и русского языков) : автореф. дис. ... канд. филол. наук. Тюмень. 20 с.

Гращенков Н. В., 2015. Теоретическая основа для изучения эвфемизмов и их интерпретация в иноязычной аудитории // Актуальные проблемы гуманитарных и естественных наук. № 11-2. C. 167-173. 
Логунова К. А., 2014. Эвфемизмы в дипломатическом языке // Филологические науки. Вопросы теории и практики. № 12 (42), ч. 2. C. 109-112.

Москвин В. П., 2001. Эвфемизмы: системные связи, функции и способы образования // Вопросы языкознания. № 3. С. 58-71.

Порохницкая Л. В., 2012. Концептуальная метафора и метонимия как основа сопоставления эвфемизмов разных языков (на материале французского, испанского и итальянского языков) // Вестник Московского государственного лингвистического университета. № 10 (643). C. 120-128.

Сребрянская Н. А., Мартынова Е. А., 2011. Антиутопия как вид политического дискурса // Вестник Воронежского государственного университета. Серия «Лингвистика и межкультурная коммуникация». № 2. С. 122-125.

Шейгал Е. И., 2000. Семиотика политического дискурса. Волгоград : Перемена. 368 с.

Яровая Л. С., 2012. Способы образования эвфемизмов в английском языке // Вестник Пятигорского государственного лингвистического университета. № 8. С. 110-113.

Damjanović D. Z., 2017. Types of Information Warfare and Examples of Malicious Programs of Information Warfare // Vojnotehnički glasnik. Vol. 65, br. 4. S. 1044-1056. DOI: https://doi.org/ 10.5937/vojtehg65-13590.

Harris Z. S., 1952. Discourse Analysis // Language. Vol. 28, № 1. P. 1-30. URL: https://studylib.net/ doc/25193085/discourse-analysis.

Ilyinova E. Yu., Kochetova L. A., 2016. Diachronic Perspective in Text and Discourse Studies // Beстник Волгоградского государственного университета. Серия 2, Языкознание. Т. 15, № 4. C. 18-25. DOI: https://doi.org/10.15688/ jvolsu2.2016.4.2.

Kunerth J., 2006. To Put it Another Way is Euphemism's Role // The Sun. Jun. 21. P. 25. URL: https:// www.sun-sentinel.com/news/fl-xpm-1986-06-218602060575-story.html (date of access: 02.10.2019).

\section{ИСТОЧНИКИ И СЛОВАРИ}

Эпштейн - Эпштейн М. Гоппи. Новая молодежная субкультура? Нет, государственная // Новая газета. 2017. 13 нояб. (№ 126).

Beowulf: The Internet Wiretap Edition : From The Harvard Classics / transl. by Gummere. URL: http:// manybooks.net/titles/anonetext97bwulf1 1.html (date of access: 21.10.2019).

Digital War. URL: https://www.digital-war.org (date of access: 21.10.2019).
Essential American English Dictionary. URL: https:// dictionary.cambridge.org/dictionary/essentialamerican-english (date of access: 21.10.2019).

Essential British English Dictionary. URL: https:// dictionary.cambridge.org/dictionary/essentialbritish-english (date of access: 21.10.2019).

Etymology Dictionary. URL: https:/www.etymonline.com (date of access: 21.10.2019).

Falkner W. Soldier's Pay. URL: https://bookfrom.net/ william-faulkner/34431-soldiers_pay.html (date of access: 21.10.2019).

Hamingway E. A Farewell to Arms. URL: https:// libcat.ru/knigi/proza/klassicheskaya-proza/ 314824-ernest-hemingway-a-farewell-toarms.html (date of access: 21.10.2019).

Havelok the Dane / ed. by R. B. Herzman, G. Drake, E. Salisbury. URL: https://d.lib.rochester.edu/ teams/text/salisbury-four-romances-of-englandhavelok-the-dane (date of access: 21.10.19).

Middle English Dictionary. URL: https:// quod.lib.umich.edu/m/middle-english-dictionary/ dictionary (date of access: 21.10.2019).

Military History Encyclopedia. URL: http:// www.historyofwar.org/articles/concepts_war.html (date of access: 21.10.2019).

Old English Translator. URL: https:// www.oldenglishtranslator.co.uk/index.htm (date of access: 21.10.2019).

Poroshenko - Poroshenko: Russia Leads a Hybrid War Against the Entire Free World. URL: https:// en.topwar.ru/134576-poroshenko-rossiya-vedetgibridnuyu-voynu-protiv-vsego-svobodnogomira.html (date of access: 21.10.2019).

Sir Gawain and the Green Knight / transl. by J. L. Weston. URL: http://www.lib.rochester.edu/Camelot/ sggk.htm (date of access: 21.10.2019).

What-is-information-warfare? URL: https:// www. weforum.org/agenda/2015/12/what-isinformation-warfare (date of access: 21.10.2019).

\section{REFERENCES}

Belov V.A., 2018. Vzaimozamenyaemost kak kriteriy sinonimii (eksperimentalnoe i korpusnoe issledovanie) [Interchangeability as the Feature of Synonymy (Experimental and Corpus Research)]. Vestnik Sankt-Peterburgskogo universiteta. Yazyk i kultura [Vestnik of Saint Petersburg University. Language and Literature], vol. 15, no. 3, pp. 390-407. DOI: https://doi.org/ 10.21638/spbu09.2018.306.

Venediktova L.N., 2004. Kontsept «voyna»v yazykovoy kartine mira (sopostavitelnoe issledovanie na materiale angliyskogo $i$ russkogo yazykov): avtoref. dis. ... kand. filol. 
nauk [The Concept of "War" in the Linguistic Picture of the World (A Comparative Study on the Material of English and Russian Languages). Cand. philol. sci. abs. diss.]. Tyumen. 20 p.

Grashchenkov N.V., 2015. Teoreticheskaya osnova dlya izucheniya evfemizmov i ikh interpretatsiya $\mathrm{v}$ inoyazychnoy auditorii [Theoretical Basis for the Study of Euphemisms and Their Interpretation in a Foreign Audience]. Aktualnye problemy gumanitarnykh i estestvennykh nauk, no. 11-2, pp. 167-173.

Logunova K.A., 2014. Evfemizmy v diplomaticheskom yazyke [Euphemisms in Diplomatic Language]. Filologicheskie nauki. Voprosy teorii i praktiki [Philological Sciences. Issues of Theory and Practice], no. 12 (42), part 2, pp. 109-112.

Moskvin V.P., 2001. Evfemizmy: sistemnye svyazi, funktsii i sposoby obrazovaniya [Euphemisms: Systemic Links, Functions and Ways of Formation]. Voprosy yazykoznaniya [Topics in the Study of Language], no. 3, pp. 58-71.

Porokhnitskaya L.V., 2012. Kontseptualnaya metafora i metonimiya kak osnova sopostavleniya evfemizmov raznykh yazykov (na materiale frantsuzskogo, ispanskogo i italyanskogo yazykov) [Conceptual Metaphor and Metonymy as a Basis for Comparing Euphemisms ofDifferent Languages (The Study of French, Spanish and Italian Euphemisms)]. Vestnik Moskovskogo gosudarstvennogo lingvisticheskogo universiteta [Vestnik of Moscow State Linguistic University], no. 10 (643), pp. 120-128.

Srebryanskaya N.A., Martynova E.A., 2011. Antiutopiya kak vid politicheskogo diskursa [Antiutopia as a Type of Political Discourse]. Vestnik Voronezhskogo gosudarstvennogo universiteta. Seriya: Lingvistika $i$ mezhkulturnaya kommunikatsiya [Proceedings of Voronezh State University. Series: Linguistics and Intercultural Communication], no. 2, pp. 122-125.

Sheigal E.I., 2000. Semiotika politicheskogo diskursa [The Semiotics of Political Discourse]. Volgograd, Peremena Publ. 368 p.

Yarovaya L.S., 2012. Sposoby obrazovaniya evfemizmov $\mathrm{v}$ angliyskom yazyke [Methods for the Formation of Euphemisms in the English Language]. Vestnik Pyatigorskogo gosudarstvennogo lingvisticheskogo universiteta [Pyatigorsk State Linguistic University Bulletin], no. 8, pp. 110-113.

Damjanović D.Z., 2017. Types of Information Warfare and Examples of Malicious Programs of Information Warfare. Vojnotehnički glasnik, vol. 65, br. 4, S. 1044 1056. DOI: 10.5937/vojtehg65-13590.

Harris Z.S., 1952. Discourse Analysis. Language, vol. 28, no. 1, pp. 1-30. URL: https://studylib.net/ doc/25193085/discourse-analysis.
Ilyinova E.Yu., Kochetova L.A., 2016. Diachronic Perspective in Text and Discourse Studies. Vestnik Volgogradskogo gosudarstvennogo universiteta. Seriya 2, Yazykoznanie [Science Journal of VolSU. Linguistics], vol. 15, no. 4, pp. 1825. DOI: https://doi.org/10.15688/jvolsu2.2016.4.2.

Kunerth J., 2006. To Put It Another Way Is Euphemism's Role. The Sun, June 21, p. 25. URL: https:// www.sun-sentinel.com/news/fl-xpm-1986-06-218602060575-story.html (accessed October 2, 2019).

\section{SOURCES AND DICTIONARIES}

Epshtein M. Goppi. Novaya molodezhnaya subkultura? Net, gosudarstvennaya [Goppy. New Youth Subculture? No, State One]. Novaya gazeta, 2017, November 13, no. 126.

Beowulf. The Internet Wiretap Edition. From The Harvard Classics. Translated by Gummere. URL: http:// manybooks.net/titles/anonetext97bwulf1 1.html (accessed 21 October 2019).

Digital War. URL: https://www.digital-war.org (accessed 21 October 2019).

Essential American English Dictionary. URL: https:/ /dictionary.cambridge.org/dictionary/essentialamerican-english (accessed 21 October 2019).

Essential British English Dictionary. URL: https:// dictionary.cambridge.org/dictionary/essentialbritish-english (accessed 21 October 2019).

Etymology Dictionary. URL: https:// www.etymonline.com (accessed 21 October 2019).

Falkner W. Soldier's Pay. URL: https://bookfrom.net/ william-faulkner/34431-soldiers_pay.html (accessed 21 October 2019).

Hamingway E. A Farewell to Arms. URL: https:// libcat.ru/knigi/proza/klassicheskaya-proza/ 314824-ernest-hemingway-a-farewell-toarms.html (accessed 21 October 2019).

Herzman R.B., Drake G., Salisbury E., eds. Havelok the Dane. URL: https://d.lib.rochester.edu/ teams/text/salisbury-four-romances-of-englandhavelok-the-dane (accessed 21 October 2019).

Middle English Dictionary. URL: https:// quod.lib.umich.edu/m/middle-english-dictionary/ dictionary (accessed 21 October 2019).

Military History Encyclopedia. URL: http:// www.historyofwar.org/articles/concepts_war.html (accessed 21 October 2019).

Old English Translator. URL: https:// www.oldenglishtranslator.co.uk/index.htm (accessed 21 October 2019).

Poroshenko: Russia Leads a Hybrid War Against the Entire Free World. URL: https://en.topwar.ru/ 134576-poroshenko-rossiya-vedet-gibridnuyuvoynu-protiv-vsego-svobodnogo-mira.html (accessed 21 October 2019). 
Sir Gawain And The Green Knight. Translated by Jessie 1. Weston. URL: http://www.lib.rochester.edu/ Camelot/sggk.htm (accessed 21 October 2019).
What-Is-Information-Warfare? URL: https:// www. weforum.org/agenda/2015/12/what-isinformation-warfare (accessed 21 October 2019).

\section{Information About the Authors}

Natalia A. Srebryanskaya, Doctor of Sciences (Philology), Professor, Department of the English Language, Voronezh State Pedagogical University, Lenina St., 86, 394043 Voronezh, Russia, srebryan@mail.ru,https://orcid.org/0000-0002-8958-9725

\section{Информация об авторе}

Наталья Анатольевна Сребрянская, доктор филологических наук, профессор кафедры английского языка, Воронежский государственный педагогический университет, ул. Ленина, 86, 394043 г. Воронеж, Россия, srebryan@mail.ru, https://orcid.org/0000-0002-8958-9725 